\title{
Las rentas episcopales
}

\author{
RICARDO MONTOLÍO HERNÁNDEZ
}

\begin{abstract}
RESUMEN
Las notables disfuncionalidades existentes en el sistema de dotación de culto y clero hacian inaplazable, en las postrimerías del Antiguo Régimen, la modificación de la distribución y asignación de rentas eclesiásticas. El ambiente político propio del Trienio

Liberal (1820-1823), constituirá la ocasión propicia para un primer ensayo de reforma en profundidad que vendrá condicionada por dos elementos concurrentes: el exigido arreglo general del clero y las perentorias necesidades de la Hacienda. Dada su entidad y complejidad, la Archidiócesis de Toledo puede servir como ajustado modelo ejemplificador del proceso.
\end{abstract}

PALABRAS CLAVE Rentas eclesiásticas, Dotación de culto y clero, Trienio Liberal, Arreglo general del clero, Archidiócesis de Toledo, Junta diocesana, Partícipes laicos, Comisiones diocesanas.

\section{ABSTRACT}

Remarkable disfunctionalities in the worship and clergy fund providing systems made it impossible to postpone, at the end of the Ancient Regime, the distribution and assignment modification of ecclesiastical rents. The political environment of the three-year Liberal Period (1820-1823) would provide the favourable occasion for a first and deep reform test that would be dependent on two attendant elements: the required general clergy arrangement and the urgent needs of the Exchequer. Due to its entity and complexity, the Archdiocese of Toledo may serve as a fitted exemplifying model of the process.

KEYS WORDS

Ecclesiastical income, Worship and clergy allocation, General arrangement of clergy, Diocesan committee, Secular members, Diocesan assemblies. 
Las rentas episcopales en España como, en general, las del resto de los estamentos eclesiásticos, se nutrían de los rendimientos generados por sus propiedades rústicas, procedentes de una acumulación secular por vía de donaciones, legados piadosos de diversa procedencia -reyes, nobleza, clero y feligresía en general-y, en menor medida, de las adquiridas a título oneroso, de las propiedades urbanas e industriales, con idéntico origen, de sus inversiones en forma de juros o censos y, desde luego, la fuente más relevante, como en el resto de las categorías eclesiásticas, de su participación en la contribución decimal, además de en otras formas de exacción.

La participación en las rentas decimales constituirá, pues, la fuente de ingresos más importante tanto en lo que hace a su montante, como por servir de criterio de referencia para la actuación del intervencionismo estatal en las rentas de las mitras a través de diversos expedientes y en particular, extremo que en este trabajo resulta de capital importancia, por medio del establecimiento de las denominadas pensiones sobre las mitras.

Una aproximación al montante de las rentas episcopales derivadas de su participación en la exacción decimal resulta dificultado por la ausencia de datos seguros y porque las estimaciones globales que en su momento se hicieron venían influidas con más frecuencia de la deseable por los intereses o, sobre todo en el tiempo en el que se intenta someter a reforma el sistema, coincidiendo con la ola liberal, las inclinaciones políticas de quien calculaba.

Así las cosas, los cálculos difieren notablemente y son, en general, de relativa fiabilidad, como muestran las estimaciones que se ofrecen a continuación. En el extremo superior, el cálculo efectuado por Canga Argüelles en la primera edición de su Diccionario de Hacienda, recoge la cifra de 1.525.085.120 reales ${ }^{1}$, mientras que Madoz fijará las rentas del clero secular y regular para 1835 en 1.481.682.144. Otras estimaciones resultarán más modestas y, probablemente, más ajustadas a la realidad. La Tesorería General calculó, a partir del importe de las tercias y noveno, que el diezmo para 1808 ascendería a seiscientos millones de reales y la Memoria que se presentó al Congreso en $1820^{2}$, estimaba su valor en

1 Canga Argüelles en su Diccionario de Hacienda, Londres 1826, t. 2, pp. 94 a 96 , advierte que esta cifra se ofrece «a falta de datos seguros» $y$, de hecho, la omitió en la segunda edición de la obra.

2 Memoria sobre los presupuestos de los gastos, de los valores, de las contribuciones y rentas públicas de la Nación española, y de los medios para cubrir el déficit que presenta a las Cortes ordinarias de 1820 D. José Canga Argüelles, Secretario de Estado y del Despacho Universal 
335.694 .000 reales, mientras que la Comisión de Hacienda, en 1821, buscando aproximarse a la realidad calculaba que su valor se acercaba a los quinientos millones de reales, cuantía que tampoco fue admitida por buen número de diputados que la situaban un poco por encima de los doscientos millones ${ }^{3}$.

Independientemente de las inclinaciones sesgadas que en cada ocasión se manifiestan y las propias dificultades que para su cálculo acreditan, el diezmo fue un ingreso muy variable que durante el sexenio 18141820 debió oscilar alrededor de los cuatrocientos millones de reales ${ }^{4}$, siendo necesario precisar que de esa cantidad aproximadamente la mitad era transferida bien al Estado, bien a los partícipes laicos ${ }^{5}$.

Sea cual fuere su montante final, una vez abandonada la práctica del acervo común y la ideal división en cuatro partes adecuadas a las necesidades de los preceptores: obispo, clero, pobres e iglesias, y disponiendo obispo e iglesias catedrales de la administración de sus ingresos decimales, sobre ellas recaerían, tanto las partidas para atención de los necesitados de la diócesis como, y en buena medida, ab inictio al menos, relacionadas con esta vocación, las cargas de pensiones en su primera concepción.

Sobre la participación episcopal en esta nutrida partida de ingresos se ejercerá, una vez más, la intervención del la Corona a través de un expediente alambicado como es el referido de las pensiones que presentará dos aspectos complementarios de control de esta jerarquía eclesiástica: el económico, más próximo a esta exposición, pero, también y sin duda trascendental, el ideológico y de fidelidad personal e institucional de los candidatos a las sedes episcopales, a través del mecanismo de presentación, la aneja obligación de asumir el compromiso de pago de la pensiones establecidas sobre la mitra de que se tratare y otros compromisos adiciona-

de Hacienda de España y Ultramar - leída en las sesiones de 13 y 14 de julio de 1820. Palacio, 7 de julio de 1820. DSC, 13 de julio de 1820, núm. 9 (apéndice).

3 . Es el caso del obispo de Sigüenza y diputado por Palencia, Manuel Fraile, para el que la suma de las percepciones decimales se situaría en los doscientos once millones de reales, siendo ésta la cantidad que se obtenía de multiplicar por nueve los veinte millones de reales en que cifraba el noveno el propio Ministerio de Hacienda, a lo que añadía once millones por tercias reales y veinte millones del excusado. DSC, 22 de mayo de 1821 p. 1775.

4 Esteban CANALES, «Hacienda, Iglesia y Diezmos durante el Trienio Liberal (1820-1823)», en «O Liberalismo na Península Ibérica na primeira mitade do século XIX». Lisboa., 1982, Vol. I, p. 206, mantiene la tesis de que en 1821 el montante de las percepciones decimales completas rondaría los trescientos cincuenta millones de reales.

5 Para el diputado Sierra Pambley solamente la participación del Estado en el diezmo alcanzaría los cinco novenos. Diario de Sesiones de Cortes, 22 de mayo de 1821, pp. 1760 y 1761 
les que el futuro o promovido obispo habría de asumir antes de su postulación formal ante la Santa Sede.

Presentación de candidatos e imposición de condiciones económicas anejas a la ocupación de la sede episcopal aparecerán así como dos elementos complementarios y concatenados en el tiempo de la actuación de la potestad regia en el marco del real patronato.

Como con toda exactitud señala Barrio Gozalo ${ }^{6}$, mediante la Bula Eximie devotionis affectu, otorgada el 6 de septiembre de 1523 por el Papa Adriano VI, Carlos V obtiene para sí y sus sucesores el derecho de patronato y de presentación de personas idóneas a todas las iglesias catedrales de las coronas de Castilla y Aragón. Con esta Bula confirmada por Clemente VII en 1530 y por Paulo III en 1536 y sumadas las concesiones anteriores referidas a las iglesias del reino de Granada, Canarias, América y Pamplona, culmina con éxito la pretensión de la monarquía española de control de las provisiones episcopales y que se extenderá, en lo sucesivo, al discurrir de la carrera eclesiástica del nominado, asegurando, en definitiva, la dependencia de la jerarquía eclesiástica de la Corona.

La actuación práctica del mecanismo de provisión de sedes episcopales discurrirá en adelante y sin cambios sustanciales hasta el final del Antiguo Régimen por los cauces establecidos por Felipe II y señaladamente en el marco de las disposiciones contenidas en la Instrucción de 6 de enero de 1588. Norma esta de capital importancia para el ejercicio de control regio, pues a través de los informes reservados en ella prevenidos la selección de candidatos quedaría en lo sucesivo en el ámbito de decisión del monarca y de su aparato político administrativo.

Momento de especial interés en el estudio del establecimiento e incidencia de las pensiones sobre las mitras, es, pues, el del nombramiento de nuevos obispos, en el que desde la Cámara se exigía la remisión de informes relativos a las pensiones existentes sobre la sede vacante, distinguiendo entre las llamadas vivas y las vacantes, su importe y las rentas medias del obispado computadas, generalmente, por quinquenios. A través de este trámite se podía calcular el volumen de gravamen que habría de corresponder en ese tiempo a la mitra por aplicación de la graduación de tasas existente y a través de su comparación con las pensiones que se venían abonando, la cantidad efectiva a percibir y, en su caso, la posibilidad de nuevas imposiciones.

6 Barkio Gozalo, M. «La Santa Sede y el nombramiento de los obispos españoles al final del Antiguo Régimen" en / Congreso Virtual de Historia Contemporánea de España. Universidad Nacional de Educación a Distancia. Madrid, 2000. 
El proceso de nombramiento de un nuevo obispo pone con frecuencia de manifiesto las tensiones generadas entre la práctica regalista y la resistencia de la Santa Sede, polos de un contencioso permanente entre el Papado que creaba las pensiones, que por esencia dependían y se legitimaban en la autoridad eclesiástica, y el rey que las imponía y que alcanzaron su cenit en las concesiones a favor de extranjeros y los continuados fraudes de ley - cedulas bancarias - a que su prohibición, en tiempos de Carlos V, dio lugar? De ahí la reiteración en las bulas de la observación de que la concesión se efectúe motu proprio y no a instancia del beneficiario ni de otro en su nombre, es decir, por efecto de la mera liberalidad papal y, por su parte, el escrupuloso control ejercido por la Cámara a través de los informes fiscales.

El monarca en ejercicio del regio patronato proponía el candidato seleccionado entre los considerados idóneos por la Cámara, quien, previamente, debía prestar consentimiento a las cargas económicas impuestas a la mitra que habrá de ocupar. Dicho consentimiento, que se solemnizaba como juramento formal impuesto como obligación a los obispos por Felipe $\checkmark$ y que debería alcanzar entre un tercio y un cuarto de sus rentas, aparece como el reverso laico de la consagración, refiriéndose esencialmente a la materias prevenidas en la Nueva Recopilación y en la Recopilación de Indias, es decir, aspectos relacionados con las prerrogativas regias ${ }^{8}$, y finalizaba con la fórmula genérica del compromiso de guardar todo lo perteneciente al real Patronato y de no impedir la Jurisdicción real en manera alguna ${ }^{9}$ en el marco del juramento civil a que los propuestos estaban obligados desde tiempos de los Reyes Católicos ${ }^{10}$.

Efectuado lo anterior, la propuesta se remitía al representante de España ante la Santa Sede, acompañada del poder otorgado por el designado, documento este en que, de nuevo, obran las condiciones que desde la monarquía se imponían al candidato con especial referencia a las cargas de pensiones, cláusula que se incluirá de forma sistemática y con carácter sustancial en todos los procedimientos de presentación de obispos hasta el final del Antiguo Régimen e, incluso, con posterioridad a la muerte de Fernando VII ${ }^{11}$.

\footnotetext{
Nov. Recop., lib. I, tit. XXIII.

Nueva Recopilación: Ley XIII, Lib. I, Tit. III; Recopilación de Indias, Ley I, Tit. VII, Lib. I.

AHN. Consejos. Leg. 16891.

Nov. Recop., lib. I, tit. VIII, ley 1 a $^{\mathrm{a}}$ Recop. de Indias, lib. I. Tit. VII, ley $1 .^{\text {a }}$.

En el caso del poder otorgado por D. Félix Torres Amat, en 1834, se hace constar «...Que por cuanto la Magestad del Rey N. Sr. D. Fernando Séptimo (que Dios guarde) ha sido servido de nombrarle y presentarle para la Iglesia y Obispado de Astorga, que es de su Real Patronato Ecco..., con carga de la tercera parte de pensión que corresponde según el valor del último quinquenio...” AHN. Consejos. Leg. 16.891.
} 
El Pontífice, a su vez, y con ocasión del otorgamiento de la bula de consagración, forzado a reconocer las pensiones hasta la cuantía máxima que en su caso correspondiese, sin perjuicio de que en la realidad éstas se viesen reducidas del porcentaje inicial, buscará imponer ciertas estipulaciones, especialmente referidas a debilitar la dependencia del nuevo prelado de la autoridad real ${ }^{12}$.

En el mismo documento se precisaban las formas de pago, las cláusulas de caución a través de una excepción de carácter general que aseguraba el derecho reconocido frente a cualquier interferencia normativa 0 privilegios particulares del obispo o sus sucesores y las penas por incumplimiento que sancionaban al obispo moroso y que, dado el volumen de pleitos generados al respecto y de las constatación documental de retrasos e incluso incumplimiento en los pagos, no debieron resultar especialmente eficaces ${ }^{13}$.

La bula papal en búsqueda, cuando $m$..us, de un equilibrio de potestades, podía incluir, además de cláusulas generales referidas a la formula de juramento de fidelidad que debía prestar a la Santa Sede según el que se reforzaba la dependencia de Roma, la defensa del pontificado y de las regalías de San Pedro y promover los derechos, honores, privilegios y autoridad del Papa, comprometiéndose a no ser «autor por obra, consejo ni trama de que se maquine ninguna cosa siniestra contra el mismo Papa ni contra la iglesia Romana o perjudicial a la persona, honra, Derecho o estado y potestad de él o de ella", obligándose además a un largo etcétera que comprendía el dar cumplida noticia al Papa de cualquier operación que pudiese serle perjudicial, otras particulares referidas a aspectos concretos de la actuación de nuevo prelado en su respectiva sede, vg.: relativas al mantenimiento del seminario Conciliar, Monte Pío diocesano $u$ otras.

Pasada la bula a la Cámara por el fiscal, se elevaba informe orientado a controlar cualquier exceso que pudiere producirse por parte de Roma en perjuicio de los derechos y prerrogativas del Patronato Real. En concreto que el juramento que había de prestarse a la Santa Sede lo fuere sin per-

12 La fórmula de la bula de consagración rezaba: «Te conferimos el Encargo de Obispo y Pastor ...hemos concedido que se reservase una o más pensiones anuales hasta la cantidad de .... favor de las personas que se nombraren por Nos o por el Pontífice Romano que en adelante fueren y que sean del agrado y aceptación del sobredicho Rey...»Ibidem.

13 En 1767, la Mitra de Toledo adeudaba por retrasos al Monasterio de El Escorial 334.400 reales; en 1814, D. José de la Fuente, pensionado con 200 ducados sobre la Mitra de Astorga, habrá de entablar pleito con su obispo para que se le satisficiesen los retrasos de varios años, consecuencia, según se decía, de la inmediata guerra. AHN. Consejos. Legs. 17.057 y 16.980 . 
juicio de la fidelidad debida a Su Majestad y en cuanto no perjudicase las regalías, leyes del reino y legítimas costumbres o cualquier otros derechos adquiridos, extremos que deberían constar en el texto del juramento, duplicado del cual, una vez efectuado, se debía remitir a la Cámara. La oposición del fiscal se extenderá, asimismo al asunto del Monte Pío, cuestión considerada también de competencia estatal ${ }^{14}$.

Si las condiciones de afinidad y fidelidad a la Corona junto a los méritos eclesiásticos y virtudes religiosas constituían, como queda constatado en los informes que la Cámara elaboraba y, en su caso, remitía al monarca, un componente esencial en su postulación - vg.: Decreto de 3.02.1696, primando la condición de miembro de la Inquisición para ocupar vacantes de mitras ${ }^{15}$ - no resultaría menos importante, como queda visto, la aceptación de las condiciones económicas anejas a la posesión de la sede que el candidato, como previa condición, había de asumir.

Las pensiones sobre los obispados, de muy remoto origen, no se encuadraban inicialmente en el concepto de beneficio eclesiástico, sino en el de beneficencia ${ }^{16}$. Obtenidas como privilegio por el Rey de España junto con el derecho de presentación de obispos en 1523, se sistematizaron

14 La oposición del fiscal asumida por la Cámara a las supuestas desmesuras de la Santa Sede, se intensifica a medida que la presión regalista se hace más evidente. Así, con motivo del nombramiento como obispo de D. Antonio López en 1783, aquel sostiene que: «Primeramente, la bula que viene dirigida al S.M. debe quedar y conservarse en la secretaría del Real Patronato como así se practica por punto general con semejantes Bulas en resguardo y preservación del Patronazgo Real ...La Bula de Vasallos del Obispado ...se debe retener a único efecto interpone el fiscal para ante S.S. la suplicación correspondiente por muchas razones que son obvias: pues ni el concilio provincial en lo antiguo cuando el Metropolitano confirmaba las elecciones canónicas de los obispos ni la Santa Sede después de las reservas debe mezclarse en estos señoríos temporales dimanados de la Corona poniéndose en esta bula la nota de quedar retenida para que no se use de ella en tiempo alguno. En lo que mira a exigir montes de Piedad, es propio de la inspección del Consejo dar a este fin las órdenes oportunas donde y cuando la necesidad lo pidiere no debiendo la Corte Romana gravar a los provistos en Mitras de estos reinos, sin el Real asentimiento...

Por lo tocante al origen del Patronato de la Iglesia de Astorga, suplica en lo que sea necesario el fiscal de la cláusula en que se cifra su origen solamente de indulto Apostólico no derogado por asistir a la Corona los demás títulos que constan de la leyes del reino. Últimamente en cuanto a la fórmula del juramento que debe restar el obispo electo y confirmado de Astorga, pide el fiscal se entienda sin perjuicio de la fidelidad debida a S.M., Regalías de la Corona, concordatos, usos, costumbres y demás derechos adquiridos, anotándose así al dorso de esta fórmula y remitiendo el Prelado testimonio a la secretaría del Real Patronato del referido juramento con estas salvedades y reservas. Solo cumplidos esto requisitos entiende el fiscal que cabe expedir las ejecutoriales y entregar la bulas al propuesto como obispo". Idem. Leg. 16.981

15 Idem, Leg. 17.415

16 La pensión eclesiástica tiene su fundamento en la necesidad de otorgar medios decorosos de subsistencia a los clérigos imposibilitados por edad o enfermedad de servir a la lglesia y responde a un sentimiento de humanidad y justicia más bien que un beneficio, aunque tiene con éste varias semejanzas. 
normativamente en el derecho real en tiempos de Felipe II, incorporando desde ese momento las características que les serán propias hasta fines del Antiguo Régimen. Sin perjuicio de todo ello una abundante regulación de desarrollo, adoptada generalmente con carácter de oportunidad vendrá a flexibilizar su régimen jurídico adaptándolo a las necesidades, bien de orden económico general o particular de los obispados afectados, bien a las propias exigencias de la Hacienda real ${ }^{17}$.

Así, si originariamente el límite impuesto para esta carga se cifraba en un tercio de las rentas episcopales líquidas, Felipe III se verá compelido a suavizar - que no derogar la primitiva tasa- su imposición por resultar excesivamente gravosa y una Orden de 1611, firmada por el duque de Lerma, establecía que no excediesen del cuarto de la renta líquida del correspondiente obispado, sin embargo, durante el reinado de Felipe IV, las urgencias de la Hacienda real y la vigorosa política del Conde Duque impulsaron un endurecimiento en su exacción.

En cualquier caso, la voluntad, no siempre de fácil ejecución, de armonizar las precisiones de la Hacienda con las disponibilidades económicas de los obispados llevará paulatinamente a la graduación de la imposición, fijando su cuota porcentual en razón del volumen de las rentas líquidas de los obispados y estableciendo tres categorías entre ellos: los más ricos

\footnotetext{
Sus orígenes remotos se encuentran en los Concilios de Efeso y Calcedonia. Mas avanzados los tiempos los mismos Romanos Pontífices empezaron a conceder pensiones de dicha naturaleza y con tanta liberalidad que en el Concilio de Trento se protestó de aquella generosidad, acordándose que no se gravase en adelante con ningunas pensiones o reservas de frutos iglesia alguna o catedral, cuyas rentas no excediesen de la suma de mil ducados, ni las de las parroquiales que no suban de cien ducados (cap. XIII, De reform. Sesión 24). La deriva desde la originaria concepción puede rastrearse en la práctica que de la misma se hizo por la Corona: desde su otorgamiento a pueros para financiar sus estudios, a su concesión a laicos como remuneración de servicios varios, reales o no, a la Corona, con lo que ni la tardía exigencia, impuesta en 1799, de que deberían necesariamente recaer en tonsurados parece que tuviera virtualidad.

17 Ordenanzas de Castilla dadas por Felipe If (06/01/1588). Novísima Recopilación de la Leyes de España L. I, Tit. XVII, Del Patronato Real y L. IV, Tit. IV, de la Cámara de Castilla y conocimiento de los negocios en ella. El Patronato Real de las Indias, L. I, Tit. VI, Ley 1-1i. Madrid, 1805. En cualquier caso, la pugna por el control de la institución venía de lejos. Las soluciones se plasmarán en sucesivas normas orientadas a limitar la liberalidad papal y a su sometimiento a la potestad regia. Así las pragmáticas de D. Carlos y D. ${ }^{a}$ Juana y más tarde la de Felipe II (leyes $1 .^{a}$ y 2. ${ }^{a}$, tit. XXIII, lib.I de la Novísima Recopilación), en que se prohibió a los extranjeros obtener pensión sobre los beneficios, salvo que los naturales lo consintiesen. El Concordato de 1737, en su artículo 14, dispuso, con algunas salvedades, que S.S. vendría en no imponer pensiones sobre las parroquias de España. La disposición que terminó las cuestiones suscitadas con motivo de las pensiones eclesiásticas en España, fue el art. $8^{\circ}$ del Concordato de 1753 , pues concedido al Rey Católico el derecho del Real Patronato, tal facultad llevó unida la de no imponerse en adelante pensiones ni aun sobre los cincuenta y dos beneficios que quedaban reservados a la exclusiva colación del Papa.
} 
que quedarán gravados hasta un tercio de su valor; los medianos hasta la cuarta parte, mientras que los más pobres quedarían exentos ${ }^{18}$.

En esta línea de adecuación del gravamen a la realidad y a los imperativos económicos efectivos de las diócesis se prodigará una extensa regulación, de carácter general unas veces, más particularizada otras. Entre la primera, el Decreto de 6 de mayo de 1670, por el que se manda repartir las pensiones del Arzobispado de Santiago, Granada y otros ${ }^{19}$; la Orden de 30 de diciembre de 1764 por la que se abre la posibilidad de revisar el importe de las pensiones en relación con las rentas debidamente justificadas y que excediesen de un tercio de las rentas líquidas del obispado y que trae causa en el recurso presentado al Rey por los obispos de Cuenca y Sigüenza en que solicitaban se moderasen las pensiones a proporción de lo que habían bajado las rentas ${ }^{20}$ así como la disposición de 31 de diciembre del mismo año por la que se establecían normas procedimentales para la aplicación de la orden anterior. Más recientes las Órdenes de Fernando VII de tres de marzo y seis de julio de 1827 por las que, respectivamente, se fija el máximo de pensiones a percibir en un tercio de las rentas de la mitra y se establecen normas para fijar las pensiones sobre aquélla ${ }^{21}$.

En cuanto a la regulación de carácter particular, más abundante, se orienta con criterio de oportunidad a favorecer a nuevos destinatarios o a su redistribución o reasignación en atención a criterios de prioridad. Así ocurrirá en los repetidos subsidios acordados por Resolución de Carlos III de 1764, al príncipe Clemente de Sajonia, su cuñado, en la cuantía de 2.000 doblones de a sesenta reales de cuenta sobre los arzobispados y obispados en que hubiese vacantes o vacaren en los reinos de la Corona de Castilla y Aragón ${ }^{22}$ y Orden del mismo monarca de 24 de mayo del mismo año por el que se le conceden otros 6.000 doblones sobre rentas eclesiásticas ${ }^{23}$.

Más, en el orden de atender requerimientos de mayor amplitud, la Orden de 6 de mayo de 1754 por la que se conceden 2.000 doblones sencillos de

18 En una relación de 1682, dentro de la primera categoría entrarían, excluyendo los de la Corona de Aragón, once, representando 220.732 ducados de pensión; los de la segunda diecinueve, con 83.411 ducados, quedando exentos los obispados de Mondońedo, Lugo, Orense, Almería, Guadix y Ceuta. AHN. Consejos, Lib. 2.726.

9 Idem. Leg. 15.264.

Idem. Lib. 266.

Idem. Leg. 16.980.

Solicitud tramitada por el marqués de Grimaldi a D. Nicolás Manzano en fecha 09.03.1764, encargándole al mismo tiempo que solicite de Roma las correspondiente bulas. Idem. Lib. 266.

23 Ibidem. 
pensión sobre las mitras para que sirvan de dotación a las capillas de los ministros en las cortes protestantes de Londres, Copenhague, Estocolmo y Petersburgo ${ }^{24}$ y en relación con lo que pudiera acercarse más a la finalidad primera de la institución, la Orden datada en 1763 por la que las pensiones que gravaban las mitras de Teruel, Vic, Tarazona, Huesca, Tarragona y Abadía de Ripio, establecidas a favor del Hospital de Aragón de Madrid, se prorrogasen automáticamente cada 14 años, una vez verificado el tipo de cada una de ellas, o la también Orden de 12 de noviembre de 1764 por la que se disponía la perpetuidad de la pensión de 24.508 reales y 30 maravedís, cargada sobre la tercera parte del valor de la mitra de Zaragoza a favor del Hospital General de Zaragoza ${ }^{25}$.

Tampoco el concepto de liquidez aplicado a este concreto asunto permanecerá inalterable. Por Real decreto de Fernando VI de 1746, se permitirá deducir de las rentas íntegras el importe del subsidio y excusado y todos los demás que pagase la Mitra, así como todos los gastos de administración y desde 1775 se podrá incluir entre esas deducciones los sueldos de los ministros y dependientes que se tuviesen por indispensables para la administración general de la diócesis.

La tasa y el volumen de la exacción aparecen, de este modo, del todo condicionadas a las precisiones del momento y podrán sufrir alteraciones al alza de importancia. Tal sucederá, por ejemplo, cuando por las referidas Órdenes de Carlos III, de 9 de marzo y 6 de junio de 1764, se manda aplicar al Príncipe Clemente de Sajonia 20.000 ducados en pensiones sobre los obispados y arzobispados y otros tantos para la dotación de las capillas de los ministros en Londres, Copenhague, Estocolmo y Petersburgo, para lo que habrá que proceder a un recuento y redistribución de cuotas entre las diócesis ${ }^{26}$, generando una situación de indeterminación jurídica fuente de constantes controversias ${ }^{27}$.

Por su importe, las pensiones cargadas sobre los obispados que, siguiendo a Domínguez Ortiz, se elevarían a finales del siglo XVIl a trescien-

24 Ibidem.

25 Ibidem.

26 En el mismo sentido la tardía Resolución de dos de julio de 1827, conteniendo normas para fijar las pensiones sobre las mitras.

${ }_{27}$ Entre otras muchas y en este caso por tratarse de una tramitación reglada de orden institucional, de especial significado, la evidenciada en el informe remitido en 1826 por el Obispo de Astorga a la Cámara de Castilla, con el expresivo título: «El Obispo manifestando la imposibilidad en que se encuentra de satisfacer las pensiones impuestas sobre la mitra». AHN, Consejos, leg. 16.980. Los bruscos incrementos de la prestación, bien referidos al conjunto de los obligados, bien a uno solo de ellos, no fueron infrecuentes: v.g.: el señalamiento, en 1800, de una pensión de seiscientos mil reales sobre la Mitra Toledo a favor del Cardenal Lorenzana. 
tos mil ducados para los castellanos y a entre cuarenta y cincuenta mil en la Corona de Aragón ${ }^{28}$, eran, como se apuntó, una de las mayores contribuciones que debía soportar la Iglesia Española, a la que había que añadir la nada despreciable suma que resultaba de las pensiones sobre dignidades y canonicatos de ciertas sedes especialmente prósperas ${ }^{29}$.

Con ocasión de reordenación, redistribución y asignación de cuotas de pensión adecuadas a la realidad, se ordenó la remisión a la Cámara de los estados económicos de las diferentes diócesis. Estos registros permiten un conocimiento bastante pormenorizado de las rentas declaradas por las diferentes mitras, la revisión de las pensiones a aplicar con ocasión del nombramiento de los nuevos prelados, la tasa determinada por pensión para cada una ella y, por consiguiente, el importe que por tal concepto se había de satisfacer en lo sucesivo, los beneficiarios y, al menos en parte, los criterios aplicados para la presentación de nuevos obispos, todo ello referido a la segunda mitad del siglo $\mathrm{XVIII}{ }^{30}$.

Los datos consultados referidos a las diócesis de Ávila, Cádiz, Cartagena, Córdoba, Coria, Cuenca, Granada, Jaén, Málaga, Osma, Oviedo, Palencia, Pamplona, Plasencia, Santiago, Segovia y Sigüenza, arrojan un montante final de 284.588 ducados, de los que 51.535 - entre una quinta y una sexta parte- correspondían en exclusiva a la mitra de Santiago.

Como normativamente venía determinado, tampoco en términos porcentuales la participación de las diferentes mitras era la misma. De las citadas mayoritariamente el gravamen alcanzaba un tercio de sus rentas, mientras que en el caso de Palencia solamente sumará la cuarta parte y, muestra del rigor en el ajuste de la contribución, Ávila que hasta 1780 soportaba la imposición de un cuarto, en 1795 la verá incrementada hasta un tercio. Idéntico incremento se producirá en el caso de Cádiz en 1775 .

En lo que se refiere a los individuos promovidos a las mitras, como tiene investigado el Prof. Barrio Gozalo, el criterio de selección entre las personas «más beneméritas e idóneas», sin un necesario falseamiento, al menos sistemático, del principio, permitía un amplio grado de discreción de la Cámara y del monarca a la hora de situar en las dignidades episcopales a sus adictos y, asimismo de promoverlos en la carrera eclesiástica, criterios

28 Domínguez Ortiz, A., Las clases privilegiadas en la España del Antiguo Régimen. Madrid, 1973, pág. 375 .

29 Sobre las rentas del arcedianato de Toledo se ordenó dar en 1647, 45.000 ducados para el fondo de recursos especiales que administraba el conde de Castrillo. Domínguez Ortiz, A., Ibidem.

30 AHN. Consejos. Leg. 17.413. 
que obviamente sufrirían variaciones al compás de los tiempos, de las circunstancias políticas y concomitantemente con la voluntad del monarca.

Este proceder raramente encuentra obstáculos en Roma y la bula de consagración se otorgará en coherencia con la propuesta monárquica. Solo las turbulencias políticas propias de la España de inicio del siglo XIX enrarecerán en este extremo la connivencia entre las dos potestades y las oscilaciones entre liberalismo y absolutismo determinarán un intervencionismo romano negatorio de toda pretensión de elevar a las mitras españolas individuos de conocido talante liberal o no fervorosos absolutistas, mientras que se manifestará complaciente hasta el exceso en la acogida de los ultramontanos, jugando en este ámbito un papel decisivo la intervención de los sucesivos nuncios papales.

En cualquier caso, el trasfondo económico de la institución permanecerá inalterable. De hecho, resulta sugerente que ni en las normas básicas en que se articuló la primera reforma en profundidad del régimen económico de la Iglesia Española, adoptadas durante el Trienio Liberal, ni en la profusa y minuciosa discusión parlamentaria de que se derivarán, se manifieste intención referida a la reforma de una institución que, por las circunstancias apuntadas, parecería merecer un tratamiento riguroso. Es más, la reglamentación generada al objeto de modificar las prestaciones decimales, mientras declarará suprimidos los subsidios que pagaba el clero - medias anatas, anualidades - y apuntará fórmulas expropiatorias de bienes eclesiásticos para dar compensación a la extinción de los derechos de los partícipes laicos en la masa decimal ${ }^{31}$, expresamente mantendrá la vigencia de las pensiones que se hallaban impuestas sobre las mitras, dignidades y otros beneficios eclesiásticos

La vitalidad de la institución se pone de manifiesto en el hecho de que en las postrimerías del Antiguo Régimen desde la Corona se siga utilizando con profusión e intensidad esta fuente de recursos.

Para la diócesis de Zamora se solicita la relación de las pensiones existentes al objeto de la aplicación del Decreto de 23 de noviembre de 1796, por el que se subrogaba en el goce de ciertas pensiones vitalicias al Hospicio de la ciudad. De la relación se desprende que con ocasión del nombramiento en 1793 como obispo de D. Antonio Piñuela, su cuantía ascendía a 96.650 reales, de los que se aplicaba 6.600 al hospital Sotelo de

31 Sin perjuicio del establecimiento por Decreto LXIX, de 29 de junio de 1821, de una contribución (repartimiento) de treinta millones de reales a distribuir entre las diócesis en proporción a sus ingresos. Colección de Decretos de las Cortes, págs. 251 y 252. 
esa ciudad; 2.400 a la Orden de Carlos III y 22.000, la partida más importante, al Hospital de Madrid ${ }^{32}$.

Lejos de atenuarse, la presión por este concepto en esta diócesis concreta se incrementará notablemente y a principios del siglo XIX, con ocasión de los sucesivos nombramientos como obispos de D. Ramón Falcón y Salcedo y D. Joaquín Carrillo Mayoral, se sitúan en 150.550 reales, correspondiendo el exceso sobre el montante anterior a pensiones vitalicias a favor de particulares ${ }^{33}$.

Por bula de Pío VII de 28 de febrero de 1803, y en aplicación del Decreto de 4 de diciembre de 1796, se agregarán perpetuamente al Hospicio y Casa de Expósitos el valor de toda la tercera parte pensionable de la mitra, exceptuándose las pensiones perpetuas. En 1816 se prorroga por 14 años la pensión a favor del Hospital General de Madrid y en 1827 se prorroga por el mismo espacio de tiempo la establecida a favor de los Corregidores y Alcaldes Mayores del Reino ${ }^{34}$.

Finalmente, en 1834 y ante la justificación por parte del obispo de la imposibilidad de atender los 16.400 reales de pensión a favor del Vicariato General de los Reales Ejércitos, en aplicación de la real Orden de 3 de agosto de 1833, se ordena que se traslade dicha pensión a otra mitra más desahogada.

Especialmente ilustrativa por su volumen de rentas y, en consecuencia, de su contribución en pensiones, la mitra de Toledo ${ }^{35}$ en 1771 debía abonar por este concepto 1.152.107 reales de vellón, de los que la parte mayor, 764.319 reales, se destinaba a pensionar al Infante D. Luis. Muy alejada de la anterior pero sin duda notable la pensión que gozaba el Duque de Solferino, 103.125 reales. Por el contrario al mantenimiento del Hospital de Toledo solamente contribuía con 1.000 reales.

Sin embargo, en el periodo en que el arzobispado fue ejercido por el Cardenal Lorenzana, 1772 en adelante, la composición de los beneficiarios de pensiones advierte cambios destacables imponiéndose 44.000 reales a favor de la Orden de Carlos III; 50.000 a favor del Montepío Ministerial y 220.000 para la Casa de Caridad de Toledo.

En 1824, con ocasión del nombramiento de D. Pedro de Inguanzo y Rivero, el valor del obispado se calculó en 3.550 .874 reales y el importe

\footnotetext{
32 AHN. Consejos. Leg. 17.066.

33 Ibidem.

34 Ibidem.

35 Ibidem.
} 
máximo de la parte pensionable en 1.183 .624 reales, quedando disponibles 561.144 reales. Entre 1824 y 1825 se otorgaron pensiones por importe de 439.200 reales de los cuales 345.000 se destinaron a pensiones que podriamos denominar «institucionales»: en concreto 40.000 a las Hermanas de la Caridad de Madrid; 160.000 a la Inclusa de la misma ciudad; 15.000 al Hospital de la Latina; 40.000 para atender las reparaciones en el palacio de España en Roma y 100.000 a la Real Orden Americana. Del resto 94.200 reales se aplicaron a pensiones vitalicias a particulares y 121.944 reales quedaron disponibles.

A tenor de lo expuesto y con el carácter de aproximación crítica a la institución, pueden desgranarse algunas conclusiones. En primer lugar el desvanecimiento temprano del carácter inicial de beneficencia entre clérigos con el que la institución nació, pero más aún, la pérdida progresiva de los caracteres y requisitos que canónicamente la definían y justificaban ${ }^{36}$-las justas causas para su imposición-e incluso el requisito residual que permitiría una mayor discrecionalidad en la adjudicación de pensiones a favor de personas: tener 18 años y conocida vocación al estado eclesiástico ${ }^{37}$, se eludiría sistemáticamente, como lo acreditan no solo las pensiones a favor de pueros, sino las otorgadas en compensación de servicios de todo tipo efectuados al Estado o a la Santa Sede por todo género de personas.

Sin duda, el componente económico resulta esencial tanto por su importancia intrínseca como por su función determinante en la evolución de la institución. La pugna entre la Corona y la Santa Sede lo pondrán en evidencia. Las pensiones a favor de extranjeros y las fórmulas de elusión de su prohibición -cédulas bancarias y testaferros- serán expedientes de que Roma se servirá para disponer de unos abultados ingresos destinados, sobre todo, a sufragar su administración y diplomacia. La presión de la Monarquía por el control de los nombramientos de obispos operará en sentido inverso.

La controversia pareció alcanzar vía de solución a través del Concordato de 1753, por el que el Romano Pontífice cedió totalmente sus derechos en orden a la colación de beneficios y en consecuencia su renuncia a imponer pensiones ni aun sobre los 52 que quedaron reservados a su exclusiva colación. Los perjuicios que estos arreglos debían traer al Estado Pontificio fueron en parte indemnizados con 600.000 escudos romanos.

36 Edad o enfermedad de un clérigo que renuncia a su beneficio; atender a clérigos pobres que fuera del servicio de altar puede ser útil a la lglesia; restablecer la paz entre los litigantes, cuando el beneficio fuere litigioso; restablecer la equivalencia en caso de permuta o traslado de beneficios.

37 Nov. Recop., ley 6.". 
Tales disputas, tensiones y, finalmente, transacciones no hacen sino poner de relieve la importancia que el control y disposición de un tal volumen de recursos tenían, bien fuere en manos de la Santa Sede o de la Corona española.

Desde la vertiente de la administración real, lo cierto es que salvados los abundantes ejemplos de ejercicio abusivo comprobados, la fórmula resultará útil sin duda alguna a la financiación y mantenimiento generalizado de instituciones de interés social evidente: educativas, asistenciales, etc..., sin que sus concretas aplicaciones deban hacer perder una perspectiva más general, la de constituir un mecanismo, aunque tortuoso, de retorno a la sociedad que las había generado de parte de las rentas patrimonializadas por la Iglesia.

Cabe señalar, finalmente, el progreso a lo largo del tiempo de la tendencia a la institucionalización de la figura en la administración estatal y la configuración gradual de estos ingresos como una partida oficiosa de los presupuestos del estado y, en consecuencia, así ha quedado acreditado en el caso de la Archidiócesis de Toledo desde los inicios del siglo XIX, su aplicación a fines de interés general, bien entendido que en gran parte de los casos con un acusado matiz de beneficencia. 